\title{
Analysing the Factors Involved In Risk Management in a Business
}

\author{
Dr. Anasica S, Mrs. Sweta Batra \\ ${ }^{1}$ MGM Department, The Free University of Berlin, Germany \\ ${ }^{2}$ Department of Management Studies, Haryana India \\ Ianasica.s@ubingec.ac.in \\ ${ }^{2}$ swetabatra1985@gmail.com
}

\begin{tabular}{|c|c|}
\hline Article History & Abstract \\
\hline $\begin{array}{l}\text { Article Submission } \\
12 \text { June } 2020 \\
\text { Revised Submission } \\
28 \text { July } 2020 \\
\text { Article Accepted } \\
17 \text { August } 2020 \\
\text { Article Published } \\
30^{\text {th }} \text { September } 2020\end{array}$ & $\begin{array}{l}\text { This article explains the risk factors involved in a business. In each type of business, } \\
\text { there are certain risk factors for the implementation of anything in the business. The } \\
\text { type of risks involved can depend upon many factors. It also depends on the type of } \\
\text { business an organisation is doing. But it is very important that the risk analyst does } \\
\text { all the analysis of the risks that might arise in future and must take necessary actions } \\
\text { in order to avoid those risks. The risk analyst can also try to reduce the impact of the } \\
\text { risks on the business. Therefore, it is very important that the risk analyst should have } \\
\text { the knowledge of how to analyse risk and then can act upon them. } \\
\text { Keywords: Risk Management, Risk Analyst, Business Management }\end{array}$ \\
\hline
\end{tabular}

\section{Introduction}

The process of identifying risks involved and then try to avoid and prevent them is called as Risk Management. There is a separate team for the risk analysis whose manager will be called as Risk Analyst. He along with his team members will first of all try to understand the nature of the products and services provided by the business to the end users and then try to predict the risks factors involved with it. The job of the risk analyst is crucial as he needs to have complete knowledge of the risk analysis otherwise there are chances that he might miss some important information which could help him to identify the risks. The risk management and identification go through different stages which is known as risk management life cycle. It can be understood with the help of following diagram: -

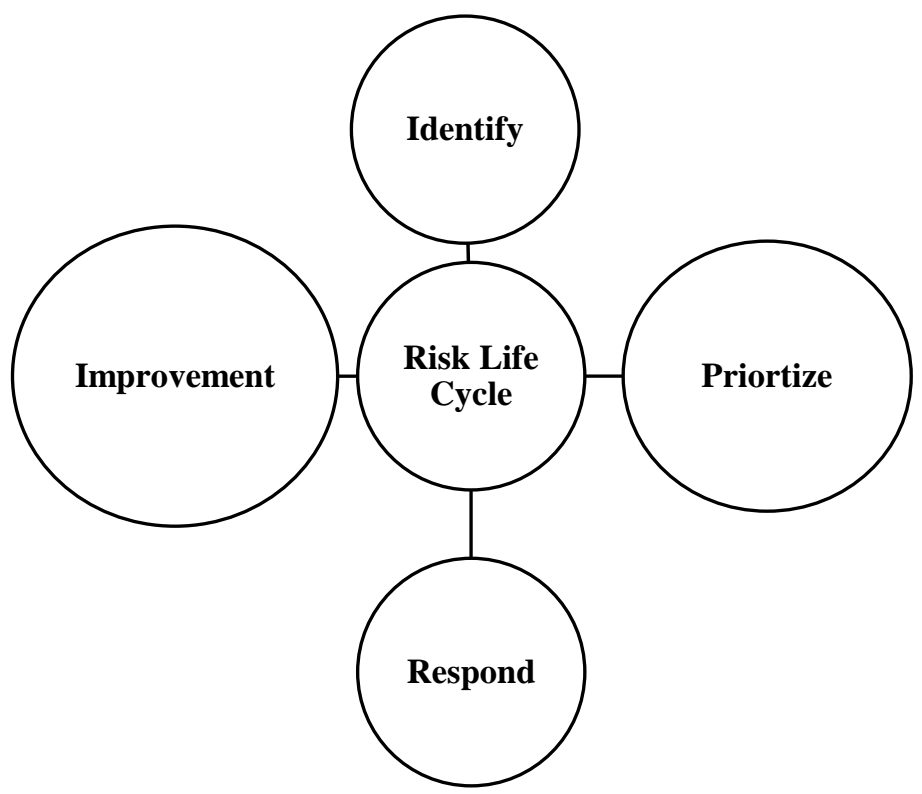




\section{Fig 1 Risk Management Life Cycle.}

- Identification of Risks: - The first step of the risk life cycle is that the Risk Analyst sits with the employees and tries to understand the nature of the product and services. He goes through all the documents related to the product and understands the process involved in development of the product/services. Based on this he will try to identify what will be the risks which might arise in the future. Then he plans with his team members that what are the factors which will result in the risks, what are the types of risk, how they are produced, what are the impacts of these risks on other business units, how to prevent them in future, how to fix them. This all will be discussed by the risk analyst with his team and then they start working on them.

- Prioritizing the Risks identified: - Now the risk analyst will have a list of all the risk factors and risks in front of him. The list will also include the impact etc about the risk. Now the risk analyst will start giving priorities to each risk mentioned in the document. He will try to give high priority to the risks which needs immediate attention and then he tries to provide solution to fix that risk. In some cases where it is impossible to avoid the risk, the risk analyst will try to find out alternate solutions or also ways to reduce the impact of the risk on other business units.

- Respond: - In this phase, the actual working on the risks will start. The risk analyst will give the solutions to solve the risk issue and also assigns the task among his team members. If he feels that the particular risk does not belong to their department then he will assign that particular risk to the department to which it belongs in real. In some scenarios the risk can be completely resolved but, in some cases, it is difficult to avoid them. So, in such cases the risk analyst will try to reduce its impact and avoid the situations which will give those risks.

- Improvement: - In this stage, the risk analyst will analyse the impact of solving the risk issue and then try to observe whether the solution given was successful or not. If yes then same solution will be documented in the risk document as a solution to be used in future. But if the impact of the solution is not so good then the risk analyst will document that as well and then will try to work and find better ways in future to fix them.

Each and every phase involved in the risk analysis life cycle is important. All the actions taken in each stage is documented well. Each phase output is the input for the other stage. Once the life cycle of the risk is finished then the whole process is repeated until a realistic solution is given or till the time prediction of all the future risks are done. Also, in case of new risk factors involved the whole process is repeated. It is the responsibility of the risk analyst to undergo each and every minute detail of the factors that will result into other risks.

\section{Types of Risks Levels:}

There are following levels of risks involved in a business: -

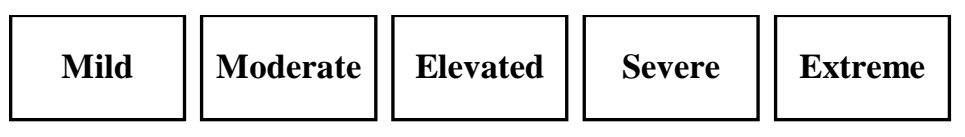

Fig: 2 Levels of Risks

1. Mild Risks: - These risks will have less impact. They are as good as invisible risks. These can be ignored. These will have very less priority to get them fixed.

2. Moderate Risks: - This type of risk will have more impact as compared to mild risks. These risks cannot be ignored. But the issue with these types of risks is that how the risks occurred is not clear.

3. Elevated Risks: - These are more important than the previous categories of the risks. These are inconsistent and every time it occurs will have new consequences. It is important to pay immediate attention to these types of risks.

4. Severe Risks: - Not to mention these types of risks will have very severe impact on the business. If these types of risks are identified, then it is the responsibility of the risk analyst to handle the risk as soon as it arises. Any delay in handling these types of risks will have severe impact. 
5. Extreme Risks: - These types of risks have high priority and have full details and are consistent. These have to reported to others and with the help of others and team it is supposed to be fixed as early as possible as this might even result in failure of the whole system. Other than risk analyst, many other high designation people are involved in these types of risks.

III. Categories of Risks: [2]

Once the risks are identified then they fall in one of the four major types of categories involved

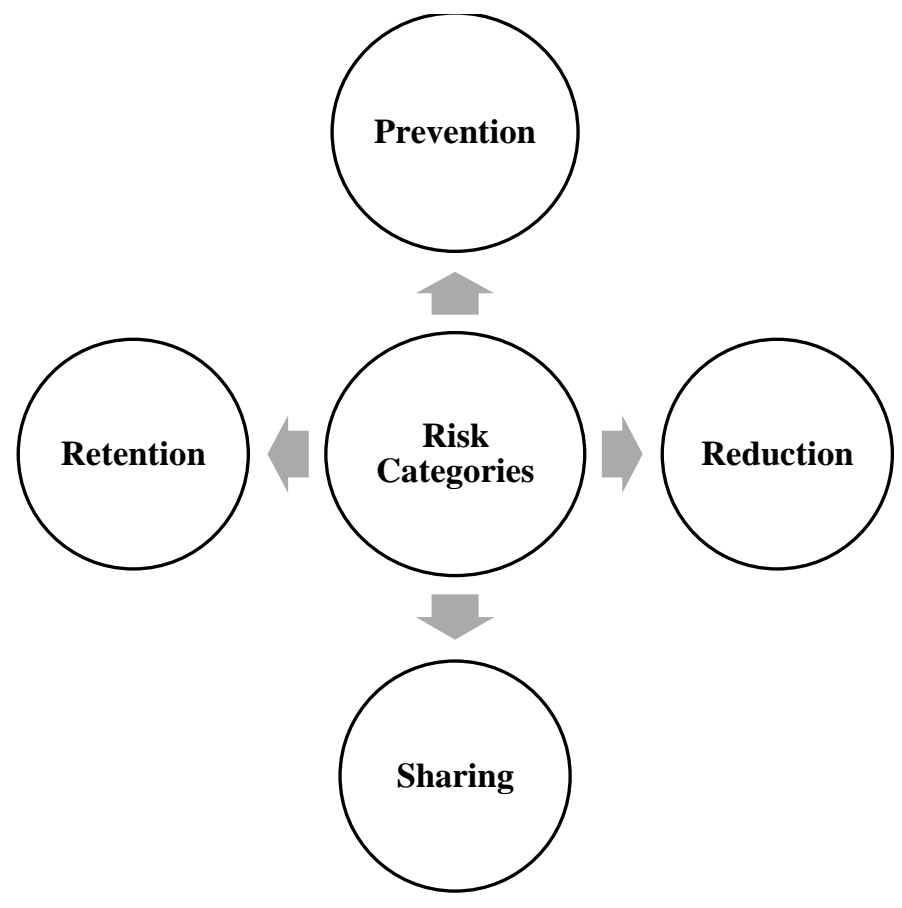

Fig 3 Categories of Risk

- Risk Prevention: - In this the known risks can be avoided by not performing the tasks which will result into risk issues. The main purpose is to avoid all those activities which might give risk threat to the business. For Example, if a land is disputed and have risks to buy it then it is better to avoid buying that land.

- Risk Reduction: - In this type, the business tries to reduce the impact of the risks on the business. In this the risk is totally not avoided but it is tried that the impact of it can be reduced.

- Risk Sharing: - In some of the risk, the impact of the risk is shared with other parties. Which means only one unit will not be responsible for this type of risk category. The loss will be shared equally among the two parties involved in this risk factor.

- Risk Retention: - The risks which fall under this category is fully owned by the business rather than transferring it to other parties. The business will take the ownership of that particular risk and will not blame other parties about the risk. This is in practice by those companies which thinks that the loss of owing the risk is less than the cost of sharing the risk from other insurance parties.

Principles of Risk Management: - Following are the principles of Risk Management System: - [3], [4]

1. Product or Service: The risks involved related to product or services provided by the business is high and should be considered. The risk analyst should analyse all the risk factors involved in the cycle of product/services provided to the customer. If the risk which might arise in future are predicted in advance then the efficiency of the products can be increased and the business can produce high quality products. 
2. Integration: The business should implement the process of risk management in all the units of the business. They should break or divide the risk analysis tasks between risk analysts of all the departments. This way a proper analysis of the risks can be done. Everything should be documented properly so that in future the other people working in risk analysis process can refer to these documents in future.

3. Keep the business goals and objectives in mind: While doing the risk analysis, the members involved in the risk analysis process should always keep the goals and objectives of the business in mind. According to this only they should make plans and should proceed the life cycle of risk assessment. If they do not keep the goals in mind then there are chances that they will deviate from the path and may end up having more risks involved in the process. Hence, the planning and identification of the risks should be always in mind.

4. Roles and Responsibilities: The risk management process involves many tasks and many team members. It is also like a project which goes parallels with the actual project. It is the responsibility of the risk analyst to first understand everything himself and then based on the capacity of his team members should assign the tasks among various team members and should guide them in case of any issues. It should be a collective process as it takes time to do proper analysis of the issues coming in a project.

5. Communication and reporting: The process of risk management involves many tasks and hence proper communication is very important. Everything should be documented at each stage of the analysis and should be accessible by all. There should be centralised database in which all the types of risks, their cause, impact, and solution should be mentioned properly in detail and should be made available to be used by all who are working in risk analysis task.

6. Use of best solution: The risk management involves the process of analysing the impact of the risk. In this the risk analyst first of all checks any available option or solution to the risk identified. If he thinks that the available solution is best way to avoid the risk then he implements that solution but if he finds out that there could be more realistic approach to solve that risk then he implements his solution. So, the process involves comparing both and implementing the best solution to the problem.

7. Understanding the warnings: In some situations it is seen that some factors will give early warnings of upcoming risks. The risk analyst should not ignore such warnings and should consider them. As, if it turns into real problem then it will be difficult to find a solution to the problem. It is the responsibility of the risk analyst to keep a track of all the warnings which arises in the system and should try to solve the issue before it becomes harmful for the system.

8. Ask for opinions: Risk management and risk analysis are a continuous two-way process. It is not only the responsibility of the people involved in the risk team but also others. Hence, the risk analyst or manager should have a proper communication with all the team members and should ask for their opinions about the risks. This will improve the risk analysis process and the business can improve its efficiency.

9. Review: This is also very important part of any process. Whatever is done should be reviewed properly and should eliminate the steps which are unnecessary and should implement new steps which are important. Each stage of the risk life cycle should be reviewed before going to the next stage.

10. Improvement: There should always be room for improvement process. Whatever mistakes are done in first cycle should be completely eliminated in next cycle. One should learn from previous mistakes and should find better ways to find a solution next time. 


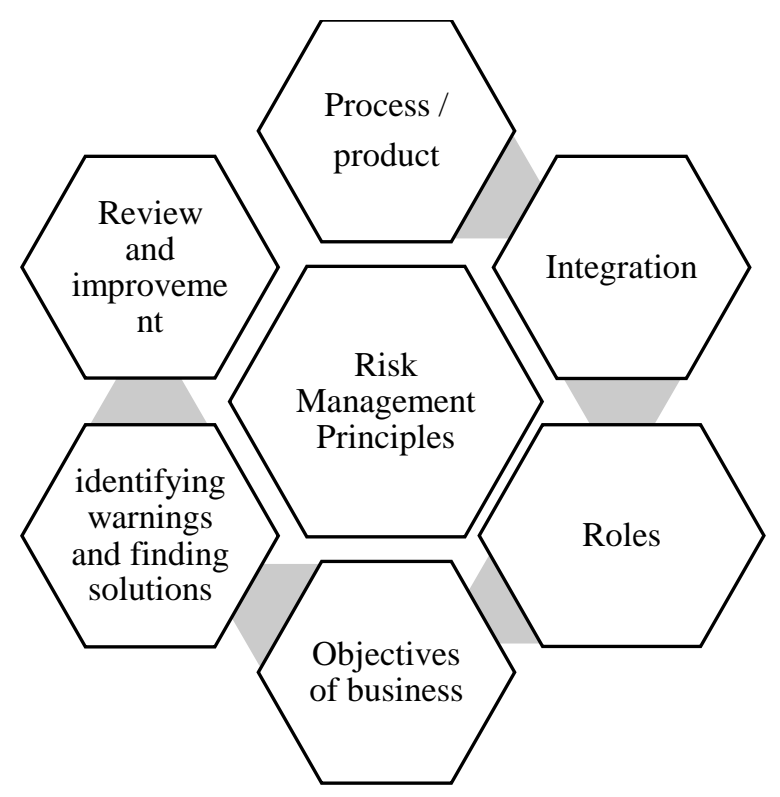

Fig 3. Principles of Risk Management

Challenges of Risk Management:
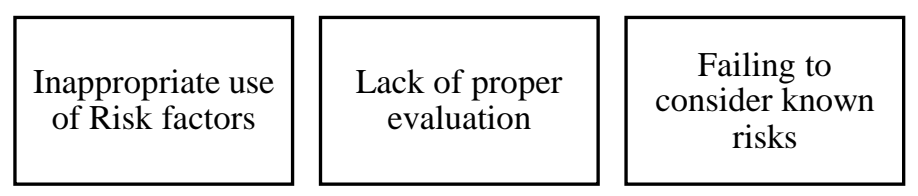

Lack of Communication

Monitoring risks

Fig 5 Challenges of Risk Management

There are challenges in every field of the business unit. The same is with the implementation of risk analysis and risk management system. They are classified as following: -

- Inappropriate use of Risk Factors: - There are certain tools available in the market for identifying the risks factors and their impact and the losses which they will make. But there is limitation of each tool and hence they can never give appropriate numbers of the impact of risks on the business. Hence it is very crucial to fully identify the impact of the risks involved in the system.

- Lack of Proper Evaluation: - This is also one of the drawbacks of the risk management system. The risk analyst are human beings and they tend to make mistakes. Hence, in some cases they can do wrong calculations than the actual ones and the result may even be failure of the system. Hence, they should always try to cross check. There can even be separate team who can review the risk analysis process to make sure that all the work done is perfect.

- Failing to consider known Risks: - Sometimes it is impossible to consider all the risks at the same time. This is the biggest challenge where the risk analyst should be capable of identifying which risks are important to be considered and which are not.

- Lack of Communication: - All the risk management and risk analysis report should be given to the top authorities to take proper actions. For this it is very important that the information is communicated properly to them If the risk analyst failed to do so then the decision made by the top managers will be according to the quality of information provided to them which may not end up in having good solution.

- Monitoring Risks: - It is very difficult to so risk analysis and to monitor the risks at the same time. This happens because it is the tendency of the risks to change their nature so quickly that it goes unnoticed by the risk analysts. 


\section{Conclusion}

It is concluded that in any business it is important to have risk analysis and risk management teams. They work according to the type of business as organisation is doing. The life cycle of risk should be followed and the risks should be eliminated based on their priority and the impact which they have on the business. There are many challenges in implementation of the risk management. Hence it is very important that the risk analyst follow the guidelines and should take the help of the tools available in the market to make their job little easy.

\section{References}

[1] Aabo, T., Fraser, J. R. S., \& Simkins, B. J. (2005), The rise and evolution of the chief risk officer: Enterprise risk management at Hydro One, Journal of Applied Corporate Finance, 17(3), 62-75. doi:10.1111/j.1745-6622. 200500045.x

[2] Abrams, C., J, V. K., Müller, S., Pfitzmann, B., \& Ruschka-Taylor, S. (2007), Optimized enterprise risk management, IBM Systems Journal, 46(2), 219-234.

[3] Ai, J., Brockett, P. L., Cooper, W. W., \& Golden, L. L. (2012), Enterprise risk management through strategic allocation of capital, Journal of Risk and Insurance 79(1), 29-55. doi:10.1111/j.15396975.2010. 01403.x

[4] Aiken, M., \& Hage, J. (1971), The organic organization and innovation, Sociology, 5(1), 63- 82. doi:10.1177/003803857100500105

[5] Alboali, S., hamid, E., \& Moosavi, S.A. (2013). The study of contingency components roles in the design of municipals' accounting systems: A case study, Journal of Business and Management Science, 1(5), 96-104. doi: 10.12691/jbms-1-5-3

[6] Allayannis, G., \& Weston, J. P. (2001), The use of foreign currency derivatives and firm market value, Review of Financial Studies, 14(1), 243-276. doi:10.1093/rfs/14.1.243

[7] Altuntas, M., Berry-Stölzle, T. R., \& Hoyt, R. E. (2011), Implementation of enterprise risk management: Evidence from the German propertyliability insurance industry, Geneva Papers on Risk \& Insurance, 36(3), 414-439. doi:10.1057/gpp.2011.11

[8] Alviniussen, A., \& Jankensgård, H. (2009), Enterprise risk budgeting: Bringing risk management into the financial planning process, Journal of Applied Finance, 19(1/2), 178-192. Retrieved from http://www.fma.org/Publications/JAFIndex.htm

[9] Andrews, R., \& Beynon, M. J. (2011), Organizational form and strategic alignment in a local authority: A preliminary exploration using fuzzy clustering, Public Organization Review, 11(3), 201-218. doi:10.1007/s11115-010-0117-4

[10] Andriole, S. J. (2009), Boards of directors and technology governance: The surprising state of the practice, Communications of the Association for Information Systems, 24(22), 373-394. Retrieved from http://aisel.aisnet.org/cais/

[11] Archer, D. (2002), Creating a risk management framework, CMA Management, 76(1), 16-19.

[12] Arena, M., Arnaboldi, M., \& Azzone, G. (2010), The organizational dynamics of enterprise risk management, Accounting, Organizations and Society, 35(7), 659-675 doi: 10.1016/j.aos.2010.07.003 Aretz, K., Söhnke M. B., \& Dufey, G. (2007), Why hedge? Rationales for corporate hedging and value implications, The Journal of Risk Finance, 8(5), 434-449. doi:10.1108/15265940710834735 